\title{
Evidence of Physiotherapeutic Interventions for Acute LBP Patients
}

\begin{abstract}
Objective: To identify the current evidence for acute low back pain $(L B P)$ treatment techniques and to amalgamate this information into a clinically applicable algorithm for South African physiotherapists.
\end{abstract}

Study design: Systematic review.

Methods: Computerized bibliographical databases were systematically searched during September 2006 and October 2006 for primary and secondary research reporting on the efficacy of various physiotherapeutic treatment techniques for acute LBP. A search for clinical guidelines regarding acute LBP was also undertaken. Evidence levels were allocated to the primary and secondary research retrieved. Results: Twenty-one systematic reviews, four randomized controlled trials and eleven clinical guidelines were included in this review. There is Level 1 evidence that advice to stay active, McKenzie preferential exercises and spinal manipulative therapy (up to six weeks) is beneficial in the initial treatment of acute LBP. There is level 2 evidence that stability exercises, dry needling, heat wrap with exercises, cognitive behavioural therapy, printed patient education, massage (with education and exercises), and lifestyle modification might be potentially beneficial in the treatment of acute LBP. There is level 1 evidence that bed rest should not be recommended for simple acute LBP. Should a patient not resolve in six weeks, red and yellow flags should be re-assessed, or patient should be referred to a specialist.

Outcome: Based on the current evidence, a composite algorithm was developed to assist South African physiotherapists when making treatment decisions for acute LBP.

Conclusion: There seems to be a lack of evidence for the efficacy of common treatment techniques used by physiotherapists in the management of acute LBP, indicating an urgent need for physiotherapy-specific, high-quality clinical trials. It is suggested that the evidence-based algorithm that has been developed, be used in the management of acute LBP to standardize physiotherapy intervention in South Africa.

\section{KEY WORDS: ACUTE LOW BACK PAIN, PHYSIOTHERAPY, SYSTEMATIC REVIEW, CLINICAL GUIDELINES.}

\section{INTRODUCTION}

Low back pain (LBP) is the most prevalent musculoskeletal condition and the most common cause of disability in developed nations (Woolf and Pfleger 2003). The lifetime prevalence of LBP (at least one episode of LBP in a lifetime) in developed countries is reported to be up to $85 \%$ (Walker 2000). Findings of a recent systematic review indicate that LBP prevalence among Africans is comparable to developed nations (Louw et al 2007). LBP management presents a major challenge to healthcare professionals working at primary care level (Deyo and Phillips 1996). The economic costs of healthcare are increasing globally, while health budgets are decreasing (van der Roer et al 2005). Thus, health professionals such as physiotherapists require cost-effective, evidencebased methods to treat LBP successfully (Avery and O'Driscoll 2004).
To date, many therapeutic interventions to manage LBP have been performed and studied, but no single treatment has been proven to be obviously superior compared with another (Heymans et al 2005). Consequently there are discrepancies between countries, between health professionals managing LBP and between practitioners of the same profession. A lack of recognising scientifically sound clinical guidelines and research recommendations from randomised clinical trials, leads to confusion and often contributes towards variability in LBP management. In order to assist clinicians in accessing evidence based information, a clinicianfriendly, systematic summary of the best practice is required.

The purpose of this review was thus to identify the evidence for acute LBP treatment techniques and to amalgamate this information into a clinically appli- cable algorithm for South African physiotherapists. The information presented may also guide medical aid schemes, with respect to tariff structures for the management of acute LBP by physiotherapists.

\section{METHODOLOGY}

Search strategy

One reviewer independently searched the following computerized bibliographical

\section{CORRESPONDENCE TO:}

Professor Quinette Louw

Division of Physiotherapy

Stellenbosch University

P O Box 19063

Tygerberg 7505

South Africa

Tel: 27219389300

Fax: 27219311252

Email: qalouw@sun.ac.za 
databases: Pedro, Pubmed, PsychInfo, Biomed, Scopus, Cochrane, BMJ.com, Digital Dissertation, Web of Science, and Cinahl, between September 2006 and October 2006. The key words entered into the search fields were: “Acute Low Back Pain”[MeSH Major Topic], "Low Back Pain”[MeSH Major Topic], physi*, back pain, systematic review, interventions, physiotherapy, and "Physical Therapy" (Specialty), spinal manipulation/mobilisation, spinal manipulative therapy, massage, neural mobilisation, exercise, dry-needling, acupuncture, TENS, interferential therapy, heat, cold, traction, psychosocial interventions, referral patterns, education, advice, guidelines/acute low back pain.

In order to obtain the most up-to-date information, only systematic reviews published in the English language between 2004 and 2006 were retrieved. Systematic reviews were considered eligible for this review if the paper reported on the efficacy of physiotherapeutic interventions for acute LBP. Reviews that reported on general practitioner, chiropractic or other medical professionals' techniques solely and did not relate to physiotherapy, were excluded. Primary research (randomised controlled trials and controlled trials) were only considered for inclusion, if none of the secondary research included (systematic reviews or guidelines) reported on a specific physiotherapeutic intervention.

In addition to the primary and secondary research retrieved, a search for clinical guidelines regarding acute LBP was undertaken. The Internet was the main source for clinical guidelines regarding acute LBP. The key words entered into http://www.google.com were "clinical guidelines" and "acute low back pain". The article published by Holohan et al (2005) was used to trace some of the clinical guidelines (Holohan et al 2005). Only clinical guidelines published on acute LBP were included.

\section{Allocation of evidence level}

The evidence obtained from the retrieved primary and secondary research was scored according to The Joanna Briggs Institute (JBI) scale of level of evidence. The JBI hierarchy is illustrated in Table 1.

Table 1: JBI scale of level of evidence: Effectiveness

\begin{tabular}{|c|c|}
\hline Level 1 & $\begin{array}{l}\text { Evidence obtained from a systematic review of all } \\
\text { relevant RCT's }\end{array}$ \\
\hline Level 2 & Evidence obtained from at least 1 properly designed RCT \\
\hline Level 3.1 & $\begin{array}{l}\text { Evidence obtained from well designed controlled trials } \\
\text { without randomisation }\end{array}$ \\
\hline Level 3.2 & $\begin{array}{l}\text { Evidence obtained from well designed cohort case control } \\
\text { analytical studies }\end{array}$ \\
\hline Level 3.3. & $\begin{array}{l}\text { Evidence obtained from multiple time series with without } \\
\text { an intervention. Dramatic results in uncontrolled experiment }\end{array}$ \\
\hline Level 4 & $\begin{array}{l}\text { Opinion of respected authorities based on clinical experience, } \\
\text { descriptive studies or reports of expert committees }\end{array}$ \\
\hline
\end{tabular}

\section{RESULTS}

\section{Systematic review search results}

The search initially yielded 517 systematic reviews involving acute $\mathrm{LBP}$ from the 10 databases. After reviewing the titles of these hits, 224 systematic reviews were considered and the abstracts of these reviews were retrieved. After reviewing the abstracts, the full text versions were retrieved for 55 systematic reviews, which were potentially relevant papers. After reviewing the full text versions, a total of 21 systematic reviews met the inclusion criteria and were considered for the review.

The systematic reviews retrieved were conducted in the Netherlands, Australia, Norway, United Kingdom, United States of America, Germany, and Brazil. The systematic reviews reported on the efficacy of spinal manipulative therapy, back schools, massage, traction, acupuncture and dry needling, heat and cold therapy, exercise therapy, bed rest and advice to stay active, and back belt usage.

\section{Primary research search results}

Randomized controlled trials (RCT's) were located for Interferential therapy (IF), transcutaneous electrical nerve stimulation (TENS), neural mobilisation, and ultrasound, as no systematic reviews reported on these techniques.

No RCT's were retrieved for ultrasound treatment. Two RCT's reported on the efficacy of interferential therapy on low back pain. One reported on the efficacy of electrode placement and was excluded, as it did not conform to the inclusion criteria. One RCT reported on TENS. A single-case series which reported on TENS, was also located. One RCT reported on the efficacy of neural mobilisation (slump stretching) on non-radicular LBP.

\section{Guideline search results}

Currently, 19 clinical LBP guidelines are available. Eleven of these guidelines were reviewed by the authors. Seven of these guidelines were obtained by PEARLing (searching reference lists) a recent publication by the Centre for Allied Health Evidence in Australia (Holohan et al 2005).

The guidelines reviewed were:

- The European Guideline 2006 (van Tulder et al 2006)

- The NGC guideline on low back-lumbar and thoracic (acute and chronic) 2006 (Work Loss Data Institute 2006)

- The University of Michigan (USA) Guideline 2005 (University of Michigan Health System 2005)

- The New Zealand guideline 2004 (New Zealand Acute Low Back Pain Guide 2004)

- The Australian guideline 2004 (Australian Acute Musculoskeletal Pain Guidelines Group 2004)

- The NGC guideline on acute low back pain 2004 (University of Michigan Health System 2004)

- KNGF-guidelines for physical therapy in patients with low back pain 2003 (Bekkering et al 2003)

- The Dutch physiotherapy guideline 2003 (Bekkering et al 2003)

- The Norwegian Guideline 2002 (Norwegian Back Pain Network 2002)

- New South Wales guideline 2002 (NSW Therapeutic Assessment Group 2002) 
- The NICE guideline 2000 (National Institute for Clinical Excellence 2000)

\section{EVIDENCE FOR REFERREL TO PHYSIO- THERAPY}

It is believed that physical therapy/ physiotherapy services are underutilized, and that this situation could be reversed if physicians were more sensitive to what physical therapists do and better informed about the benefits of physical therapy (Ehrmann-Feldman et al 1996). There is Level 3.2 evidence indicating that early referral to physiotherapy seems to be favourable in improving prognosis of acute LBP. Waiting too long before referral to physiotherapy may increase the risk of a poor prognosis/chronicity (Bekkering et al 2005). It was found that patients who were referred to physiotherapy within a month of back injury tended to return to work within a relatively shorter period of time than those who were referred later (Ehrmann-Feldman et al 1996).

Recommendation: Appropriate timing of physical therapy referral is therefore an important factor in the rehabilitation of patients with low back pain (Ehrmann-Feldman et al 1996).

\section{EVIDENCE FOR MULTIDISCIPLINARY TEAMS AND COMMUNICATION}

Multidisciplinary programmes typically include a variety of interventions, such as exercises, back school education, workplace visits, ergonomic advice and behavioural treatment. Only one systematic review of two RCT's found that multidisciplinary treatment leads to faster return to work and less sick leave than usual care (van Tulder et al 2006).

Recommendation: It is recommended that multidisciplinary treatment programmes be considered in occupational settings for workers with sick leave for more than 4-8 weeks (Evidence Level 3.2) (van Tulder et al 2006).

\section{EVIDENCE FOR PHYSIOTHERAPEUTIC INTERVENTIONS}

\section{SPINAL MANIPULATIVE THERAPY}

In a review by Ferreira et al (2003) it was found that spinal manipulative therapy produces slightly better outcomes than placebo therapy, no treatment, massage, and short-wave diathermy for non-specific LBP of less than three months duration (Ferreira et al 2003). In a meta-analysis comparing spinal manipulative therapy to other therapies, it appears that spinal manipulative therapy may only be beneficial in the first six weeks of the LBP episode (Assendelft et al 2003). Avery and O'Driscoll (2004), on the other hand, concluded that there is insufficient evidence for the efficacy of spinal manipulative therapy for patients with acute LBP (Avery and O'Driscoll 2004). The risk of serious complications are low, as an estimate of risk of spinal manipulative therapy causing a clinically worsened disk herniation or cauda equina syndrome in a patient presenting with lumbar disk herniation is calculated to be less than one in 3.7 million cases (van Tulder et al 2005).

Recommendation: It is suggested that spinal manipulative therapy can be useful in improving pain and function in the short term (up to six weeks) management of acute LBP patients (Evidence Level 1 and 2).

\section{MASSAGE}

Massage is defined as soft tissue mobilization using the hands or a mechanical device and has been used for pain relief since the fifth century (van Tulder et al 2005). There is Level 2 evidence (1 RCT, Godfrey et al 1984) that massage may be as effective as TENS and spinal manipulative therapy for pain and function (van Tulder et al 2005). There is limited evidence showing that massage is less effective than spinal manipulative therapy after the first session, and that massage cannot be recommended as a stand-alone treatment for acute LBP (van Tulder et al 2005).

Recommendation: It is suggested that massage can be beneficial especially when combined with exercises and education in the treatment of acute LBP for pain relief, but not as a stand-alone treatment.

\section{DRY NEEDLING AND ACUPUNCTURE}

Dry-needling is defined as a technique that uses needles to treat myofascial pain in any body part (Furlan et al 2006). Acupuncture is defined as a healing technique that involves the insertion of needles into the body to promote health (Furlan et al 2005). Dry needling seems to be equally effective compared to injection therapy in acute LBP (Evidence Level 2). There is insufficient evidence that acupuncture is more effective than sham acupuncture. (Sham acupuncture is categorized as either superficial needling of the true acupuncture points, irrelevant acupuncture points, and non-acupuncture points. Placebo needles made use of devices that mimicked acupuncture, but there was no skin penetration. Pseudo-interventions used switched off-laser acupuncture devices) (Manheimer et al 2005).

Adverse effects related to dry needling and acupuncture are rare, but potential, and continue to be reported in case reports (van Tulder et al 2005). Five major adverse effects were: exacerbation of depression, acute hypertensive crisis, vasovagal reaction, asthma attack and angina (van Tulder et al 2005). Two cases of pneumothorax have been reported (van Tulder et al 2005).

Recommendation: Dry needling might be suggested as a treatment option for acute low back pain.

\section{BED REST AND ADVICE TO STAY ACTIVE \\ - Simple LBP}

There is Level 1 evidence (Meta-analysis of 2 RCT's, Malmivaara 1995, Rozenberg 2002) demonstrating that "advice to stay active" and not bed rest, during the acute phase of LBP, brings about small but consistent differences for patients with acute simple LBP (LBP without neurological deficit) in improving pain and functional status at 3-12 weeks follow-up (Hagen et al 2005).

\section{- LBP with Sciatica}

There is Level 1 evidence (Meta-analysis of 2 RCT's, Vroomen 1999, Hofstee 2002) demonstrating that "advice to rest in bed" and not advice to stay active, during the acute phase of LBP, brings about little or no effect for patients with sciatica (LBP with neurological deficit) in improving pain and functional status at 3-12 weeks follow-up (Hagen et al 2005).

Restricted activity, rest, bed rest and symptomatic analgesics are the most 
commonly prescribed treatment for LBP and sciatica (Hagen et al 2005). However, prolonged inactivity, like bed rest, leads to the deterioration of many body functions, and may therefore inhibit healing of LBP (Hagen et al 2005).

Recommendation: It is suggested that a patient with simple LBP be advised to stay active during the acute phase of LBP due to the possible harmful effects of bed rest. However, discretion is advised as this depends on the patient's occupation, and work restrictions should also be taken into consideration. Should the patient with confirmed nerve root involvement qualify for bed rest instead of staying active, bed rest should not be longer than 2-3 days.

\section{EXERCISE}

Exercise therapy involves the prescription of muscular contraction and bodily movement to ultimately improve the overall function of the individual and to help meet the demands of daily living. Results demonstrate that exercise therapy does not reduce pain or improve function in the acute phase of LBP and that there is no difference in the effectiveness of exercise therapy compared to no treatment, care provided by a general practitioner, or spinal manipulative therapy (Smidt et al 2005). Recently, however, exercise programs focusing on segmental stabilizing exercises have been introduced (Rackwitz et al 2006). Results of a recent meta-analysis demonstrated that stabilization exercises, in addition to medical management, substantially reduce recurrence at 12 and 24 months year (1 RCT: Evidence Level 2, Hides et al 2001) (Ferreira et al 2006).

Recommendation: Stabilization exercises used in conjunction with medical management can be recommended for acute low back pain to prevent recurrences and chronicity.

\section{MCKENZIE METHOD}

The McKenzie method incorporates directional preferential exercises. Direction preference is defined as the situation in which referred pain arising from the spine is reduced and transferred to a more central position when movements in specific directions are performed (centralisation) (Machado et al 2006).
One systematic review reporting on the effectiveness of the McKenzie preferential exercises for LBP has been published (Machado et al 2006). Eleven RCT's were included in this review. McKenzie preferential exercises were more effective in reducing pain and disability compared to passive therapy for acute LBP at one week follow-up (Evidence Level 1). Passive therapy included the educational booklet, ice packs massage and bed rest. McKenzie preferential exercises was found to be as effective as advice to stay active in reducing pain and was less effective than advice to stay active in reducing disability at 12 weeks follow-up (Evidence Level 1). McKenzie preferential exercises were found to be as effective as spinal manipulative therapy in reducing pain and disability in the acute stage (Evidence Level 1).

Recommendation: McKenzie (directional preferential) exercises can be recommended as a treatment option for acute LBP, in reducing pain and disability, provided the patient is classified according to the McKenzie classification list. If this classification cannot be applied, the McKenzie method is contraindicated.

\section{HEAT THERAPY}

Superficial heat methods convey heat by conduction or convection, and include methods such as heat wraps, heat pads, infra-red lamps, etc. One systematic review has been published to assess the effect of cold and heat for therapy for low back pain reporting on six trials (French et al 2006). There is Level 2 evidence that heat wrap therapy is better than the educational booklet and exercise alone, in reducing pain and disability for patients with acute LBP (Mayer et al 2005). However, the effect was small and occurred for a short time only. Heat wrap combined with McKenzie preferential exercise appears to provide addition benefit for pain and function (Evidence Level 2) (Mayer et al 2005)

Recommendation: Heat therapy can be recommended as a treatment option for acute LBP, but should be used in conjunction with exercise.

\section{COLD THERAPY}

No RCT's were located that examined the effects of cold on acute LBP. Given that it is a commonly held belief that cold is beneficial for recent onset musculoskeletal injuries, it was surprising that no studies were located that applied cold therapy specifically to acute LBP (French et al 2006). There was, however, a trial which concluded that hot packs and ice massage were not significantly different for participants with a mix of acute, subacute and chronic LBP (French et al 2006).

Recommendation: There is insufficient evidence to recommend cold therapy as a treatment option for acute LBP.

\section{BACK SCHOOLS}

A back school consists of information on the anatomy of the back, biomechanics, optimal posture, ergonomics and back exercises. One systematic review evaluating 19 trials has been published (Heymans et al 2005). Four trials have evaluated the effectiveness of back schools for acute back pain patients. There is conflicting evidence that back schools are effective in reducing pain and improving functional status, recovery, recurrences and return to work. One high quality trial reported that there were positive intermediate and long term outcomes for the effect of back schools on acute and sub-acute LBP (Evidence Level 2) (Heymans et al 2005).

Recommendation: There is insufficient evidence to recommend back schools for acute LBP.

\section{TRACTION}

The exact mechanism through which traction might be effective is unclear, but it has been suggested that traction elongates the spine, through decreasing the lumbar lordosis and increasing the intervertebral space. 24 RCT's were included in a systematic review, of which 14 reported on a mixture of acute, sub-acute and chronic LBP (Clarke et al 2006). There is conflicting evidence in the effectiveness of traction on acute LBP.

\section{- LBP without sciatica}

For patients with LBP, who may or may not have sciatica, the present evidence is that traction, as a single treatment, is no more effective than placebo, sham, no treatment, or other treatments (Evidence Level 2) (Clarke et al 2006). 


\section{- LBP with sciatica}

There is Level 2 evidence that there are no significant differences in pain outcomes and global measurement, between traction and placebo, sham or no treatment.

Recommendation: There is insufficient evidence to recommend traction as a treatment option for acute LBP.

\section{BACK BELT USAGE}

One systematic review was published on the use of back belt in the prevention of occupational LBP (Ammendolia et al 2005). The populations studied were various working populations. The results showed that there was conflicting evidence for the use of back belts in the prevention of occupational LBP.

Recommendation: There is insufficient evidence to recommend back belts for the prevention and treatment of acute LBP.

\section{INFORMATION AND REASSURANCE}

Most guidelines recommend reassuring patients, by acknowledging the pain of the patient, being supportive and avoiding negative messages. One RCT (Evidence Level 2) showed that an educational booklet, "The Back Book", decreased the number of visits to a GP for back pain. Patients receiving this experimental booklet showed greater early improvement in beliefs and functional status, but there was no effect on pain. Another RCT showed that a 15-minute session with a primary care nurse plus an educational booklet and a follow-up phone call, resulted in greater short-term patient satisfaction and perceived knowledge compared with usual care, but symptoms, physical functioning and healthcare utilization were not different (van Tulder et al 2006).

Recommendation: Educational booklets and sessions may be useful in the treatment of acute LBP.

\section{EDUCATION ON LIFESTYLE - Smoking}

Smoking is not a cause of LBP, but there is Level 3.2 evidence that smoking is a moderate risk indicator for the increase duration and frequency of the LBP episode (Leboeuf-Yde et al 1998).

Recommendation: It is recommended that patients should be advised to stop smoking or smoke less.

\section{- Body weight}

There is no indication that being overweight/obese is a cause of low back pain. However, there is evidence indicating that obesity is a risk factor for developing chronic LBP (Evidence Level 3.2) (Leboeuf-Yde et al 1999).

Recommendation: It is recommended that overweight patients must be encouraged to lose weight or referred for weight loss programmes.

\section{- Alcohol}

Alcohol consumption does not seem to be associated with LBP; however, welldesigned specific alcohol/LBP-centred studies are lacking (Leboeuf-Yde 2000).

\section{ELECTROTHERAPY MODALITIES} - Ultrasound

No RCT's were located which reported on the effect of ultrasound on acute LBP. - TENS

One RCT was located which reported on the effectiveness of TENS on acute occupational LBP (Herman et al 1994). The study was done on 58 injured industrial workers, and two groups were formed. One group received actual stimulation and the other received placebo. The results found that no benefits of TENS were detected for the treatment of acute occupational LBP when added to an active exercise regime. One single case series did however report that TENS is an effective analgesic agent for the treatment of sub-acute LBP, but more research is needed (Foster et al 1997).

\section{- Interferential therapy (IF)}

Two RCT's reporting on IF were located. When IF was compared and used in conjunction with spinal manipulative therapy, it was found that for acute LBP there was no difference between the effects of a combined therapy, nor for when these treatments were used on their own (Hurley et al 2004). In another RCT comparing IF to motorized traction and massage, it was found that there was no difference in the improvement between these two groups (Werners et al 1999). Both groups showed an improvement in pain and function.

Recommendation: There is insufficient evidence to recommend the use of Ultrasound therapy, TENS and IF in the management of acute LBP (Evidence Level 2).

\section{NEURAL MOBILIZATION}

One RCT (30 subjects only) attempted to determine if slump stretching resulted in improvements in pain, centralization of symptoms and disability in patients with non-radicular LBP (Cleland et al 2005). The study found that those patients, who received slump stretching, demonstrated significantly greater improvements in pain and centralization of symptoms, than those patients who did not (Evidence Level 2). From the above study it is suggested that slump stretching with spinal manipulative therapy and exercise were more beneficial than only spinal manipulative therapy and exercise for improving short-term disability, pain and centralization of symptoms in non-radicular LBP.

Recommendation: There is insufficient evidence to recommend neural mobilization for the treatment of acute LBP, due to the low number of subjects in the RCT.

\section{MANAGEMENT OF PSYCHOSOCIAL FACTORS}

Two RCT's were published into the effectiveness of management procedures for "yellow flags". Linton et al (2005) showed that adding cognitive behavioural interventions can enhance the prevention of long term disability in acute LBP patients (Evidence Level 2) (Linton et al 2005). Cognitive-behavioural intervention encompassed a six session structured program where participants met in groups of 6-10 people, six times, once a week for two hours. Jellema et al (2006) found that an intervention strategy exploring the presence of psychosocial prognostic factors, discussing these factors, setting specific goals for reactivation and providing educational booklet was as effective as usual care (Evidence Level 2) (Jellema et al 2005).

Recommendation: Cognitive behavioural interventions may be useful in preventing long term disability in acute LBP.

\section{SUMMARY OF BEST PRACTICE IN PATIENT FOLLOW-UP}


One RCT demonstrates that a 15minute session with a primary care nurse plus an educational booklet and a followup phone call, resulted in greater shortterm patient satisfaction and perceived knowledge compared with usual care, but symptoms, physical functioning and health care utilization were not different (van Tulder et al 2006).

Recommendation: There is insufficient evidence to suggest that patient follow-up is effective in the treatment of acute LBP. However, patient follow-up may be useful in improving patient satisfaction and perceived knowledge.

\section{RE-ASSESSMENT OF PATIENTS FAILING TO RESOLVE}

Although there is no scientific evidence on the re-assessment of patients who fail to resolve, it is recommended that patients who fail to resolve within 4-6 weeks, should be reassessed for red flags, yellow flags, or referred to a specialist (van Tulder et al 2006). However, these thresholds should be used carefully as the interval between onset and first visit to a primary healthcare provider is variable.

\section{DIAGNOSTIC IMAGING (X-RAYS)}

The results of one systematic review reporting on the association between $\mathrm{X}$-ray findings of the lumbar spine and non-specific LBP, found that degeneration (defined by the presence of disc space narrowing, osteophytes and sclerosis), is consistently and positively associated with non-specific LBP (van Tulder et al 2006). A recent review concluded that for adults younger than 50 years of age with no signs or symptoms of systemic disease, diagnostic imaging does not improve treatment of LBP (van Tulder et al 2006). For those older than 50 years, plain radiography and simple laboratory tests, can almost completely rule out underlying systemic diseases. The guidelines are consistent in the recommendation that plain X-rays are not useful in acute non-specific LBP and that X-rays should be restricted to cases suspected of specific underlying pathology (van Tulder et al 2006).

Recommendation: Although X-rays are commonly used for reassurance, there is no evidence to support this. Diagnostic tests are not routinely indicated for acute non-specific LBP.

\section{ERGONOMIC INTERVENTIONS - Kinetic handling}

A prospective stu

appears to be a difference in the lifting techniques between individuals developing LBP and those not prone to LBP (Evidence Level 3.2) (Wrigley et al 2005). Currently there are no RCT's evaluating the effect of optimal kinetic handling.

\section{- Advice for computer workers}

There is Level 2 evidence that rest breaks taken especially every 20 minutes and avoiding working on the computer for more than $75 \%$ of the work time (Evidence Level 3.2) can reduce the development of LBP and discomfort (Juul-Kristensen and Jensen 2005, Mclean et al 2001).

\section{- Ergonomics of workstations}

There are no studies evaluating the effect of ergonomic adjustments of workstations on LBP.

\section{- Sitting with a lumbar roll / lordosis support}

There is one RCT (Evidence Level 2) demonstrating that a flat foam cushion or lumbar roll can be useful. Sitting with a lordotic posture, significantly reduced back and leg pain and directs referred pain towards the low back. This study demonstrates that in general sitting environments, the use of a lumbar roll results in: 1) reductions in back and leg pain; and 2) centralization of pain (Williams et al 1991).

Recommendation: It is suggested that patients with acute LBP and those at risk of developing LBP should be advised to use a lumbar roll when sitting and to take rest breaks every 20 minutes.

\section{CONCLUSION}

Currently, there seems to be a lack of evidence for the efficacy of common treatments used by physiotherapists in the management of acute LBP. This fact, however, does not correlate with the high popularity of physiotherapy treatment among people with acute LBP. The review indicates an urgent need for physiotherapy-specific, high-quality clinical trials of the interventions that physiotherapists use daily in the management of acute LBP.

It is suggested that the evidencebased algorithm that has been developed (see attached algorithm), be applied in the management of acute LBP to stan- dardize physiotherapy intervention in South Africa. This easy-to-follow algorithm should be used in conjunction with clinical reasoning and with reference to clinical expertise.

\section{REFERENCES}

1. Ammendolia C, Kerr MS and Bombardier C (2005): Back belt use for prevention of occupational low back pain: a systematic review. Journal of Manipulative and Physiological Therapeutics 28:128-134

2. Assendelft WJJ, Morton SC, Yu EI, Suttorp MJ and Skelle PG (2003): Spinal manipulative therapy for low back pain: A meta-analysis of effectiveness relative to other therapies. Annals of Internal Medicine 138:871

3. Australian Acute Musculoskeletal Pain Guidelines Group :Evidence-based Management of acute Musculoskeletal Pain (2004) http://www7.health.gov.au/nhmrc/publications/pdf/cp94.pdf

Accessed September 28, 2006

4. Avery S and O'Driscoll M (2004): Randomised controlled trials on the efficacy of spinal manipulation therapy in the treatment of low back pain. Physical Therapy Reviews 9:146-152

5. Bekkering GE, Hendriks HJM, Koes BW, Oostendorp RAB, Ostelo RWJG and van Tulder MW (2003): Dutch Physiotherapy guidelines for low back pain. Physiotherapy 89:82-96

6. Bekkering GE, Hendriks HJM, Koes BW, Oostendorp RAB, Ostelo RWJG, Thomassen JMC and van Tulder MW (2003): National practice guidelines for physical therapy in patients with low back pain (KNGF)

http://www.nvmt.nl/upload/Low\%20Back\%2 0Pain\%20binnw..pdf

Accessed September 28, 2006

7. Bekkering GE, Hendriks HJM, Van Tulder MW, Knol DL, Simmonds MJ, Oostendorp RAB and Bouter LM (2005): Prognostic Factors for low back pain in patients referred for physiotherapy: Comparing outcomes and varying modelling techniques. Spine 30:1881-1886

8. Clarke J, Van Tulder M, Blomberg S, de Vat H, van der Heijden G and Bronfort G (2006): Traction for low back pain with or without sciatica: An updated systematic review within the framework of the Cochrane Collaboration. Spine 31:1591-1599

9. Cleland JA, Childs JD, Palmer JA, Eberhart S (2005): Slump stretching in the management of non-radicular low back pain: a pilot clinical trial. Manual Therapy (In Press)

10. Deyo RA and Phillips WR (1996): Low back pain. A primary care challenge. Spine 21:2826-2832

11. Ehrmann-Feldman D, Rossignol M, Abenhaim L, Gobeille D and Battie MC (1996): Physician referral to physical therapy in a cohort of workers compensated for low back pain. Physical Therapy 76:150-158 
12. Ferreira ML, Ferreira PH, Latimer J, Herbert R and Maher CG (2003): Efficacy of spinal manipulative therapy for low back pain of less than three month's duration. Journal Manipulative and Physiological Therapeutics 26:593-601

13. Ferreira PH, Ferreira LM, Maher CG, Herbert RD and Refshauge K (2006): Specific stabilization exercise for spinal and pelvic pain: A systematic review. Australian Journal of Physiotherapy 52:79-88

14. Foster NE, Doonan J, Baxter GD, Walsh DM, Allen JM, 1997 An investigation of the analgesic efficacy of transcutaneous electrical nerve stimulation (TENS) parameter combinations upon low back pain: A singlecase series. Physiotherapy 83(12):643

15. French SD, Cameron M, Walker BF, Reggars JW and Esterman AJ (2006): A Cochrane review of superficial heat or cold for low back pain. Spine 31:998-1006

16. Furlan $\mathrm{AD}$, Brosseau L, Imamura $\mathrm{M}$ and Irvin E (2006): Massage for low back pain (Review). The Cochrane Library, Issue 3

17. Furlan $\mathrm{AD}$, Van Tulder M, Cherkin D, Tsukayama H, Lao 1, Koes B and Berman B (2005): Acupuncture and Dry-needling for low back pain: An updated systematic review within the framework of the Cochrane Collaboration. Spine 30:944-963

18. Hagen KB, Jamtvedt G, Hilde $G$ and Winnem MF (2005): The updated Cochrane review of bed rest for low back pain and sciatica. Spine 30:542-546

19. Herman E, Williams R, Stratford P, Fargas-Babjak A, Trott M (1994): A randomized controlled trial of transcutaneous electrical nerve stimulation (CODETRON) to determine its benefits in a rehabilitation program for acute occupational low back pain. Spine 19:561-568

20. Heymans MW, Van Tulder MW, Esmail R, Bombardier C and Koes BW (2005): Back schools for non-specific Low back pain: A systematic review within the framework of the Cochrane Collaboration back review group. Spine 30:2153-2163

21. Holohan V, Deenadayalan Y and Grimmer K (2005): Evidence-based physiotherapy for acute low back pain: A composite clinical algorithm synthesized from seven recent clinical guidelines (In press)

22. Hurley DA, McDonough SM, Dempster M, Moore AP, Baxter D, 2004 A randomized clinical trial of manipulative therapy and interferential therapy for acute low back pain. Spine 29(20):2207-2216

23. Jellema $P$, van der Windt AWM, van der Horst HE, Twisk JWR, Stalman WAB, Bouter LM (2005): Should treatment of (sub)acute low back pain be aimed at psychosocial prognostic factors? Cluster randomized clinical trial in general practice. British Medical Journal 331:84 24. Juul-Kristensen B, Jensen C (2005): Selfreported workplace related ergonomic conditions as prognostic factors for musculoskeletal symptoms: the "BIT" follow-up study on office workers. Occup Environ Med. 62:188-94
25. Leboeuf-Yde C (2000): Alcohol and low back pain: A systematic literature review. Journal of Manipulative and Physiological Therapeutics. 23:343-6

26. Leboeuf-Yde C, Kyvik Ko and Bruun NH (1998): Low back pain and lifestyle: Part I Smoking. Information from a populationbased sample of 29,424 twin subjects. Spine 23:2207-13

27. Leboeuf-Yde C, Kyvik KO and Bruun NH (1999): Low back pain and lifestyle: Part II Obesity. Information from a population-based sample of 29,424 twin subjects. Spine 24: 779-83

28. Linton SJ, Boersma K, Jansson M, Svärd L, Botvalde M (2005): The effects of cognitivebehavioral and physical therapy preventative interventions on pain-related sick leave: A randomized controlled trial. Clinical Journal of Pain 21:109-119

29. Louw QA, Morris LD and GrimmerSomers K (2007): The prevalence of low back pain in Africa: A systematic review of the literature from 1800-2006 (unpublished)

30. Machado LAC, de Souza M, Ferreira PH and Ferreira ML (2006): The McKenzie Method for low back pain: A systematic review of the literature with a meta-analysis approach. Spine 31:E254-E262

31. Manheimer E, White A, Berman B, Forys K and Ernst E (2005): Meta-analysis: Acupuncture for low back pain. Annals of Internal Medicine 142:651-663

32. Mayer JM, Ralph L, Look M, Erasala GN, Verna JL, Matheson LN and Mooney V (2005): Treating acute low back pain with continuous low-level heat wrap therapy and/or exercise: a randomized controlled trial. Spine Journal 5:395-403

33. Mclean L, Tingley M, Scott RN, Richards J, 2001 Computer terminal work and the benefit of microbreaks. Applied Ergonomics. 32:225-237

34. New South Wales Therapeutic Assessment Group: Low back pain (2002) Adapted from New Zealand acute low back pain Guide, Wellington, 1997

35. New Zealand Acute Low Back Pain Guide. New Zealand Guidelines Group (2004).http://www.nzgg.org/index.cfm Accessed October 03, 2006

36. Pincus T, Vogel S, Breen A, Foster N and Underwood M (2006): Persistent back painwhy do physical therapy clinicians continue treatment? A mixed methods study of chiropractors, osteopaths and physiotherapists. European Journal of Pain 10:67-76

37. Rackwitz B, de Bie R, Ewert T and Stucki G (2006): Segmental stabilizing exercises and low back pain. What is the evidence? A systematic review of randomized controlled trials. Clinical Rehabilitation 20:553-567

38. Referral practice: A guide to appropriate referral from general to specialist services. National Institute for Health and Clinical Excellence (2000).

http://www.nice.org.uk

Accessed October 03, 2006
39. Smidt N, de Vet HCW, Bouter LM and Dekker J (2005): Effectiveness of exercise therapy: A best-evidence summary of systematic reviews. Australian Journal of Physiotherapy 51:71-85

40. The Norwegian Back Pain Network - The communication unit. Acute Low back Pain. Interdisciplinary clinical guidelines (2000). http://www.ifomt.org/pdf/Norway Acute Low Back.pdf

Accessed September 28, 2006

41. University of Michigan Health System. Acute low back pain. Ann Arbor (MI): University of Michigan Health System; 2003 Apr [rev. Oct 2004]. 13p

42. University of Michigan Health System. Acute Low Back Pain. Guidelines for clinical Care (2005).

http://cme.med.umich.edu/pdf/guideline/ backpain03.pdf

Accessed September 28, 2006

43. van der Roer N, Goossens MEJB, Evers SMAA and van Tulder MW (2005): What is the most cost-effective treatment for patients with low back pain? A systematic review. Best Practice and Research. Clinical Rheumatology 19:671-684

44. van Tulder M, Becker A, Bekkering T, Breen A, Gil del Real MT, Hutchinson A, Koes B, Laerum E and Malmivaara A (2006): Chapter 3: European guidelines for the management of acute non-specific low back pain in primary care. European Spine Journal 15: S169-S191

45. van Tulder MW, Furlan AD and Gagnier JJ (2005): Complementary and alternative therapies for low back pain. Best Practice and Research Clinical Rheumatology 19:639-654 46. van Tulder MW, Koes B and Malmivaara A (2006): Outcome of non-invasive treatment modalities on back pain: an evidence-based review. European Spine Journal 15:S64-S81 47. Walker BF (2000): The Prevalence of Low Back Pain: A Systematic Review of the Literature from 1966 to 1998. Journal of Spinal Disorders 13:205-221

48. Weiser S and Rossignol M (2006): triage of nonspecific lower-back pain. Clinical Orthopaedics and Related Research 443:147-155 49. Werners R, Pynsent PB, Bulstrode CJK, 1999 Randomized trial comparing interferential therapy with motorized lumber traction and massage in the management of low back pain in a primary care setting. Spine 24(15):1579-1584 50. Williams MM, Hawley JA, McKenzie RA, van Wijmen PM (1991): A comparison of the effects of sitting postures on back and referred pain. Spine 16:1185-91

51. Woolf A and Pfleger B (2003): Burden of major musculoskeletal conditions. Bull World Health Organization 81:646-656.

52. Work Data Institute. Low back - lumbar and thoracic (acute and chronic). Corpus Christi (TX): Work Loss Data Institute (2006):390 p.

53. Wrigley AT, Albert WJ, Deluzio KJ, Stevenson JM, 2005 Differentiating lifting techniques between those who develop low back pain and those who do not. Clinical Biomechanics 20:254-263 


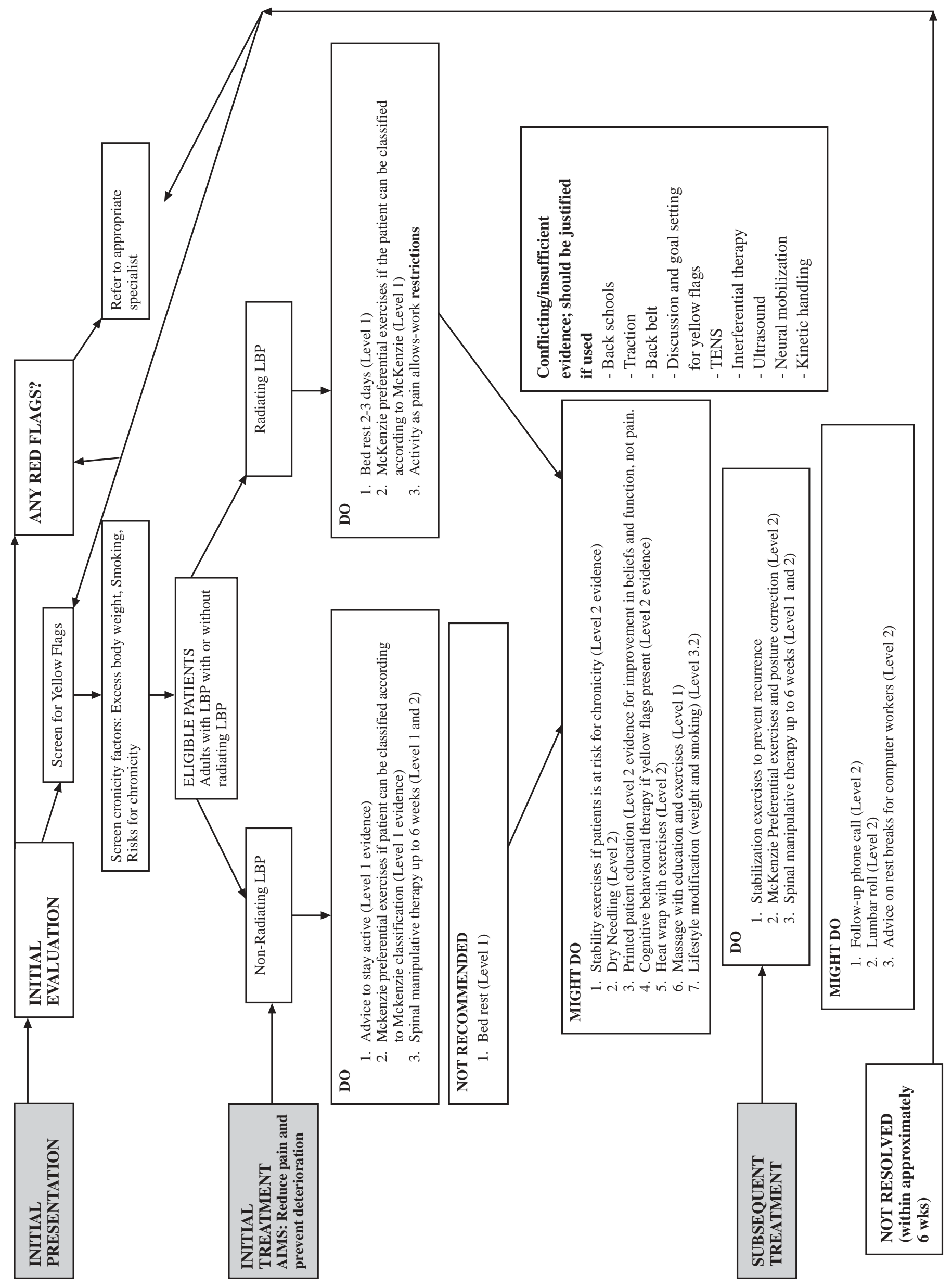

